\title{
Sobre a Psicanálise e o Envelhecimento: Focalizando a Produção Científica
}

\author{
Álvaro da Silva Santos (D, Vitória de Ávila Santos (D), Araceli Albino (D), \\ Rodrigo Eurípedes da Silveira (D), \& Giovanna Gaudenci Nardelli (D)
}

Universidade Federal do Triângulo Mineiro, Uberaba, MG, Brasil

\begin{abstract}
RESUMO - Revisão integrativa com objetivo de conhecer a produção científica em psicanálise na relação com o idoso e envelhecimento. O período considerado foi de 2011 a 2015, nas bases de dados: Index-Psicologia, LILACS e MedLine. Utilizaram-se os termos: Aged (Idoso), Elderly (Envelhecimento) e Psychoanalysis (Psicanálise). Encontraram-se 89 referências. Excluíram-se editoriais, artigos repetidos e aqueles que não se adequavam à questão norteadora deste estudo. Onze artigos foram selecionados. Ficou nítida a preocupação da psicanálise com o idoso. Essa preocupação parece preceder a questões epistemológicas, de modo que a prática clínica aparece com maior produção. Contudo, verificou-se a necessidade de um maior número de pesquisas sobre o tema.
\end{abstract}

PALAVRAS-CHAVE: idoso, envelhecimento, psicanálise

\section{Psychoanalysis and Aging: Focusing on Scientific Production}

\begin{abstract}
An integrative review aimed at knowing the psychoanalytic scientific production regarding the elderly and aging. The period considered was 2011-2015, and the databases consulted were: Index-Psychology, LILACS and MedLine. The following terms were used: Aged, Elderly, and Psychoanalysis. Eighty-nine references were identified. Editorials, repeated articles and those which did not address the guiding questions of this study were excluded. Eleven articles were considered adequate. It is clear that psychoanalysis has demonstrated interest in the elderly, which is more prevalent than epistemological questions. Therefore, clinical practice is more frequently present among the studies about the subject. However, there is a need for more research on the topic.
\end{abstract}

KEYWORDS: elderly, aging, psychoanalysis

Embora haja uma definição para idoso apenas de acordo com a faixa etária (em geral 65 anos para países desenvolvidos e 60 anos para países em desenvolvimento), sabemos que, embora essa classificação seja sociodemográfica, política, econômica, dentre outras perspectivas, não atende completamente a uma visão psicossocial e menos ainda psicanalítica. De todo modo, mesmo com esta classificação baseada na faixa etária, verifica-se que o número de idosos vem aumentando nos últimos anos e, em décadas futuras será o grupo que mais terá crescimento populacional. De acordo com o Fundo das Nações Unidas para a População (FNUAP), no ano de 2010 havia 15 milhões de pessoas idosas no mundo e, para 2051, estima-se um total de 20 milhões (Brasil, 2010). Esses dados, muito interessam à psicanálise, mesmo que, no seu início, tenha-se questionado a eficácia dessa ciência para pessoas acima de 50 anos, ideia que não mais se aplica aos dias de hoje.

Envelhecer é o destino do ser humano e também se caracteriza em uma categoria social, porém, cada sociedade vivencia formas diferenciadas no que diz respeito ao declínio biológico do indivíduo. O processo de envelhecimento envolve um contexto multivariado do desenvolvimento humano e abrange as esferas biológicas e psicológicas, mas, também, compromete as questões socioeconômicas e culturais (Alencar, 2014).

Não há dúvidas de que o surgimento da psicanálise introduziu uma nova forma de apreender o ser humano e, esclarece que os idosos estão propensos a viverem muitas perdas nesta fase da vida e a se deprimirem diante disso. A senescência traz consigo limitações e perdas de toda

* E-mail: vitoria.avila@gmail.com

- Submetido: 26/12/2016; Revisado: 05/09/2017; Aceito: 18/12/2017. 
a natureza, desde mudanças corporais, aposentadoria, mudança no status social, até a morte de entes queridos e fantasias a respeito da própria morte. Diante disso, o idoso precisa elaborar uma série de lutos e, por outro lado, necessita reinventar os padrões de vida para que descubra, também, algumas possibilidades (Altman, 2011), o que pode ser facilitado através do trabalho psicanalítico.

A psicanálise pode ser bastante útil aos idosos e pessoas em processo de envelhecimento, uma vez que pode estabelecer uma ponte entre aquilo que fomos, somos e seremos. De acordo com Cherix (2015), perdas e frustrações da velhice são frutos de vivências que tivemos ao longo da vida e que precisam ser elaboradas, mesmo que no período senil. Assim, destaca-se a relação do idoso com o tempo, uma vez que a percepção da finitude da vida pode ressaltar a sensação de desamparo e angústia. A rememoração pode surgir, então, como forma de lidar com esse mal-estar.
Estudos no campo da Psicologia Clínica, da Psicologia Social e da Psicanálise têm demonstrado as reverberações da rememoração na subjetividade de idosos. A ressignificação e reconstrução da identidade, possibilitadas pela rememoração e compartilhamento das memórias, podem ajudar o idoso a se redefinir ante as mudanças e a refazer seu lugar social e suas relações. A angústia pelo tempo que foge, talvez possa ser amenizada pelas lembranças e afetos que permanecem, e pelos ouvidos acolhedores do Outro, como é possibilitado através da prática em psicanálise (Lima, 2015).

Diante disso, percebemos a importância da valorização de práticas contemporâneas que possam auxiliar no processo de envelhecimento e, também, da necessidade epistemológica do saber psicanalítico que responda às demandas atuais. Assim, esse estudo tem como objetivo conhecer a produção científica em psicanálise na relação com o idoso e com o envelhecimento.

\section{MÉTODO}

Esta é uma revisão integrativa que considerou o período de 2011 a 2015, nas bases de dados: Index-Psicologia, LILACS e MedLine. Utilizaram-se os termos: Aged (Idoso), Elderly (Envelhecimento) e Psychoanalysis (Psicanálise). Após o levantamento, os artigos foram categorizados por similaridades temáticas e apresentados em tabelas que focalizam a referência (identificação da produção pelo autor e dados do periódico), a proposta do estudo (que sintetizam numa releitura crítica a direção do artigo - objetivo, e o caminho seguido - metodologia, sem a pretensão de copiar as afirmações dos autores da produção, por isso, a releitura crítica) e, a sinopse (que busca interpretar na leitura dos autores dos artigos as contribuições, novidades, resultados e abordagens defendidas). Excluíram-se editoriais, artigos repetidos e aqueles que não se adequavam à questão norteadora: "Qual a produção científica na relação entre a psicanálise e o idoso?".

Os resultados mostram os artigos levantados com os três itens focalizados (referência, proposta do estudo e sinopse) de cada artigo pesquisado, em ordem cronológica decrescente de publicação. Já a discussão, por sua vez, aborda os conteúdos encontrados nos artigos e a relação dos mesmos com a contribuição da psicanálise para os idosos trazendo, também, as lacunas que foram observadas pelos autores nas produções recuperadas.

\section{RESULTADOS}

O levantamento permitiu a evidenciação de 11 artigos. Em português tem-se $81,8 \%$ dos artigos (9), uma publicação em inglês e outra em francês. Os anos de 2014 e 2011 tiveram quatro publicações cada, cuja maioria (72,7\%) foi encontrada na base Index-Psi. Os estudos se qualificaram como Reflexão (7), Relato de Experiência (2), Atualização (1) e Pesquisa (1), sendo que, seis deles foram publicados em revistas específicas de psicanálise. Assim, quatro categorias foram construídas a partir do material recuperado: Clínica Psicanalitica com Idosos (sete artigos - Categoria 1), Abordagens Psicanaliticas do Envelhecimento (dois artigos - Categoria 2), Representação do Envelhecimento para Profissionais de Saúde à Luz da Psicanálise (um artigo - Categoria 3) e Geracionalidade e Psiquismo (um artigo Categoria 4).

A Tabela 1 mostra a categoria Clínica Psicanalítica com Idosos, que aborda possibilidades clínicas na intervenção com o idoso. Um dos artigos discorre acerca do uso de autobiografia, história de vida e oficinas de memória. Outra produção, aponta as possíveis contribuições da psicanálise para com os atores envolvidos numa instituição de longa permanência para idosos (ILPI), sendo estes, os profissionais cuidadores, os idosos moradores, e a própria instituição. Nesta produção, é discutida a ressignificação do cuidado para estas pessoas e a aceitação assertiva dos limites estabelecidos para todos, mantendo ao mesmo tempo, um cuidado com qualidade e uma vivência saudável tanto para o profissional cuidador, quanto para o idoso sujeito do cuidado.

Outro artigo traz como foco o sintoma. Não como sendo uma exclusividade do idoso, mas, mostrando que esse pode ter uma inscrição atemporal feita pela dimensão do inconsciente. Contudo, se esses sintomas não forem devidamente traduzidos pelo analista e, consequentemente, percebidos pelo idoso, podem de fato levar a um descaso 
Tabela 1

Categoria 1 - Clínica Psicanalítica com Idosos

Clínica Psicanalítica com Idosos. 2015 a 2013

\begin{tabular}{|c|c|c|}
\hline Referência & Proposta do Estudo & Sinopse \\
\hline $\begin{array}{l}\text { Lima PMR, Viana } \\
\text { TC, Lima SC. } \\
\text { Estética e poética da } \\
\text { velhice em narrativas } \\
\text { autobiográficas: } \\
\text { um estudo a luz da } \\
\text { psicanálise. Estudos } \\
\text { e Pesquisas em } \\
\text { Psicologia. } 2015 \text {; } \\
\text { 15(1):58-78. }\end{array}$ & $\begin{array}{l}\text { Trata-se de um artigo de } \\
\text { reflexão acerca da escrita } \\
\text { autobiográfica sob a lente } \\
\text { da psicanálise, como técnica } \\
\text { pela qual através da poética, } \\
\text { estética e história de vida, se } \\
\text { pode (re) construir o eu na } \\
\text { velhice. }\end{array}$ & $\begin{array}{l}\text { Apresentam-se os conceitos de estética e poética como modos de descrever e amenizar } \\
\text { mal estar existencial. Para tanto, cita autores que ao envelhecerem fazem autobiografias } \\
\text { que apontam a sublimação, a dessexualização e, o uso das palavras escritas como modo } \\
\text { de dar vazão as pulsões no idoso. Modo este que busca na história de vida, ferramentas } \\
\text { para se reinscrever no presente, sem deixar ao mesmo tempo de entrar em contato com } \\
\text { as vivencias do seu tempo atual (mesmo que negativas, como a dor). Ao mesmo tempo, } \\
\text { apresenta o uso de oficinas grupais das quais idosos rememoram fatos para melhor } \\
\text { lidarem com a angústia, com vistas a ressignificação da identidade e o refazer do seu } \\
\text { lugar social e suas relações. }\end{array}$ \\
\hline
\end{tabular}

Enunciam-se os conceitos de cura e cuidado, a visão negativa de se estar numa instituição geriátrica, a necessidade de manutenção do idoso na instituição de longa permanência, bem como, as fantasias que se tem sobre o cuidado recebido do profissional

Charazac PM. L'apport de la psychanalyse aux soins en institution gériatrique. Geriatr Psychol Neuropsychiatr. 2014; 12(2): 193-8.

Este é um artigo de reflexão que aponta as contribuições da psicanálise aos sujeitos do cuidado, enfermeiros e cuidadores.

Mucida A, Pinto JM Sintomas de velhos? Cad Psicanal CPRJ. 2014; 36(30):45-60.

Chessick RD. Special problems for the elderly psychoanalyst in the psychoanalytic process. J Am Psychoanal Assoc. 2013; 61(1):67-93.

Este é um artigo de reflexão que visa problematizar a ideia de sintomas de velhos, tendo como eixo indicações freudianas e lacanianas. de saúde. Todos esses aspectos no olhar psicanalítico, com valorização da intervenção do psicanalista apoiando os idosos, os profissionais e ainda o próprio funcionamento da instituição de atenção prolongada ao idoso. Com relação aos profissionais, pontua o apoio ao se fazer transferência e contra transferência, no sentido de ressignificar suas frustrações nas perdas constantes de autonomia dos idosos, ou a própria morte destes anciães, rumo à valorização deste trabalhador. Além disto, traz ainda, a possibilidade de que a cura, o cuidado, a dependência, a autonomia e a morte possam ser compreendidas e vivenciadas na importância que cada uma delas tem ora para o idoso, ora para o profissional

Aponta-se o sintoma na ótica da psicanálise em contraste com o olhar biologicista e cultural do envelhecer. Sinaliza o sintoma como podendo ser antigo, mas não específico dos idosos. Defende que a psicanálise não opera com patologias e sim com os sintomas subjetivados, na qual os sujeitos estão implicados. Nega assim os "sintomas de velhos" e, aponta em Freud que o sintoma atualiza a verdade incrustada no inconsciente. Já em Lacan descreve a questão do real e do simbólico, além de que o sintoma também

pode ser "gozo". Como alternativa à questão, descreve que a ideia geral e trágica de velhice leva muitos sujeitos a respostas sintomáticas que só tendem a aguçar os efeitos do envelhecimento; deixam de se cuidarem, desenlaçam-se da vida e tecem sintomas com os quais o corpo leva a pior, sendo que o analista é quem evidencia o sintoma no inconsciente e escuta os seres falantes, independente da idade, com vistas a fazer "emendas" entre o real e o sintoma.

Este é um artigo de reflexão que mostra condições diferenciadas do analista idoso no processo terapêutico.
Aponta-se a condição de idoso do analista ser um contexto especial que exige deste a consciência da sua existência e, um monitoramento contínuo da transferência e contratransferência evitando uma conivência silenciosa, perigosa e inconsciente de paciente e analista. A pouca literatura acerca também é apontada.

\begin{tabular}{|c|c|c|}
\hline \multicolumn{3}{|r|}{ Clínica Psicanalítica com Idosos. 2011} \\
\hline Referência & Proposta do Estudo & Sinopse \\
\hline $\begin{array}{l}\text { Silva BR, Finocchio } \\
\text { AL. A velhice } \\
\text { como marca da } \\
\text { atualidade: uma visão } \\
\text { psicanalítica. Vínculo. } \\
2011 ; 8(2): 22-8 \text {. }\end{array}$ & $\begin{array}{l}\text { Este é um relato de } \\
\text { experiência de um trabalho } \\
\text { com dinâmicas de grupo com } \\
\text { idosos de uma instituição de } \\
\text { longa permanência para idosos } \\
\text { (ILPI) com a perspectiva } \\
\text { de reflexão do idoso sobre } \\
\text { sua condição asilar e de sua } \\
\text { história de vida, sobre a ótica } \\
\text { da psicanálise. Estudo feito } \\
\text { numa cidade do noroeste } \\
\text { paulista, no ano de } 2010 .\end{array}$ & $\begin{array}{l}\text { Trata-se de uma atividade desenvolvida com } 4 \text { a } 6 \text { idosos de uma ILPI (maioria mulheres } \\
\text { - 5) de um universo de } 16 \text { moradores. Realizaram-se quatro encontros, com dinâmicas } \\
\text { de grupo que versaram principalmente acerca da percepção sobre a ILPI, história } \\
\text { familiar, histórias boas e ruins de vida, objetos representativos e orientação alimentar. } \\
\text { As narrativas mostram um silêncio sobre a ILPI com sintomas que tentam proteger os } \\
\text { desejos; a fantasia de um marido ideal apesar de traição, num contraste de pulsão de vida } \\
\text { e de morte; repetição de lembranças como único investimento de vida restante. Verificou- } \\
\text { se assim a desvalorização do saber do idoso; sentimento de abandono e desamparo; } \\
\text { comunicação pouco tolerada pelas instituições; apagamento dos traços individuais; e, } \\
\text { relatos repetitivos de histórias. }\end{array}$ \\
\hline
\end{tabular}




\begin{tabular}{|c|c|c|}
\hline \multicolumn{3}{|r|}{ Clínica Psicanalítica com Idosos. 2011} \\
\hline Referência & Proposta do Estudo & Sinopse \\
\hline $\begin{array}{l}\text { Altman M. O } \\
\text { envelhecimento à luz } \\
\text { da psicanálise. Jornal } \\
\text { de Psicanálise. 2011; } \\
\text { 44(80):193-206. }\end{array}$ & $\begin{array}{l}\text { Este é um artigo do tipo relato } \\
\text { de experiência e de reflexão } \\
\text { que aborda perdas vividas pelo } \\
\text { idoso, isto feito através de } \\
\text { conceitos psicanalíticos. }\end{array}$ & $\begin{array}{l}\text { Aponta-se que velhice não é um conceito plural, pois modela as diferentes visões. } \\
\text { Mostra o olhar no espelho como a "traição" ao corpo nas condições do envelhecer. Em } \\
\text { Freud discutem o luto como as perdas psíquicas, bem como a pouca elasticidade de uma } \\
\text { pessoa acima de } 50 \text { anos ter proveito da prática analítica. Outros autores descrevem } \\
\text { que é mais importante a idade da neurose do que a idade cronológica. A experiência da } \\
\text { autora em uma clínica social atuando com idosos mostrou a necessidade de se trabalhar } \\
\text { a elaboração de perdas e do luto, bem como, a reinventar padrões de vida. Verificava-se } \\
\text { perda de autoestima, narcisismo ferido e assim, perda de sentido de vida. Para alguns, } \\
\text { na atividade era necessário desvincular os idosos da libido de certos objetos e condições } \\
\text { e facilitar a revisão de tal libido a outros contextos. Expõe ainda a dificuldade de alguns } \\
\text { analistas, tanto de atender como de se relacionar com clientes idosos, por dificuldade } \\
\text { de lidar com a morte e, ativação de seus conflitos infantis. Retomada de potenciais } \\
\text { adormecidos, melhor uso de tempo livre e criatividade, são citados como possibilidades } \\
\text { de se ressignificar a vida do idoso. }\end{array}$ \\
\hline
\end{tabular}

Chase C. The aging of Anna Freud's diagnostic profile: a re-examination and re-application of the psychoanalytic assessment for older adults. Psychoanal Study Child 2011; 65: 245-74.
Este é um artigo de atualização sobre a aplicabilidade do perfil diagnóstico proposto por Anna Freud em idosos.
Apresenta-se um estudo de caso de uma mulher de 70 anos com o uso da técnica de perfil diagnóstico de Ana Freud para uma compreensão mais clara, tanto para o diagnóstico quanto para a compreensão intra-psiquica de pessoas idosas. perante a vida durante o processo de envelhecimento refletindo, então, no sofrimento do corpo. Noutra publicação denota-se a atenção que o analista idoso deve ter na atualização de sua prática e na relação com os seus clientes, no foco da transferência e contra transferência. Uma outra produção descreve a experiência clínica de atividade em grupo numa ILPI, na qual através da história oral e da memória se busca conhecer o significado de estar idoso numa instituição. Contudo, os resultados descrevem que houve uma repetição de fatos e o silêncio sobre a instituição.

Já uma publicação em formato de relato de experiência aponta a experiência da clínica social na apresentação do luto no que diz respeito às perdas do idoso, bem como o debate entre a cronologia da neurose em relação à importância da cronologia etária. Aborda, também, a importância de ações que tragam sentidos diferentes na vida do idoso, para além das perdas, inclusive da aparência física. Outra publicação, por sua vez, apresenta como se deu e quais são as vantagens do uso da técnica de perfil diagnóstico de Ana Freud realizado com uma idosa.

A categoria Abordagens Psicanaliticas do Envelhecimento, apresentada na Tabela 2 , direciona visões psicanalíticas acerca do indivíduo idoso. Um dos artigos faz uma crítica sobre o olhar biologicista e negativo do envelhecimento em detrimento de um inconsciente que é atemporal, portanto, que não se submete a temporalidade corporal. Aborda ainda, o olhar sobre a morte física e a morte social, que é a desvalorização do idoso pela cronologia da sua condição. Por sua vez aponta, também, para a ressignificação da vida na fase da velhice, sendo que essa pode ser facilitada pela prática da psicanálise. Outra produção, aborda novamente a visão negativa do envelhecimento e acresce o medo em relação a essa fase, bem como o sofrimento e a busca incessante da felicidade citando, ainda, exemplos do uso do humor irônico como forma de enfrentamento. Esta produção aponta possíveis contribuições da psicanálise na integridade do ego do idoso, favorecendo outros modos de encarar a vida e a morte.

A categoria intitulada Representação do Envelhecimento para Profissionais de Saúde a Luz da Psicanálise, apresentada na Tabela 3, tem apenas um artigo e esse discorre sobre o olhar de trabalhadores de saúde mental acerca do envelhecimento com foco numa visão de sofrimento emocional, solidão, perdas e isolamento. Porém, ainda que em menor proporção, foca em alguns profissionais entrevistados que veem possibilidades de ser idoso e criativo, partindo de uma visão mais positiva sobre a velhice.

A Tabela 4, que também apresenta um único artigo, traz a categoria intitulada Geracionalidade e Psiquismo. A produção recuperada foca em como o psiquismo pode ser visto na evolução geracional, mostrando exemplos através de um estudo de caso com uma idosa. 
Tabela 2

Categoria 2 - Abordagens Psicanaliticas do Envelhecimento. 2011 a 2015

\begin{tabular}{|c|c|c|}
\hline Referência & Proposta do Estudo & Sinopse \\
\hline $\begin{array}{l}\text { Vilhena J, Novaes JV, } \\
\text { Rosa CM. A sombra } \\
\text { de um corpo, imagem } \\
\text { e envelhecimento. } \\
\text { Rev Latinoam } \\
\text { Psicopat Fund. 2014; } \\
\text { 17(2): 251-64. }\end{array}$ & $\begin{array}{l}\text { Artigo de reflexão } \\
\text { acerca das } \\
\text { peculiaridades } \\
\text { relacionadas ao } \\
\text { fenômeno ser velho } \\
\text { e seus impactos no } \\
\text { sujeito num olhar } \\
\text { psicanalítico. }\end{array}$ & 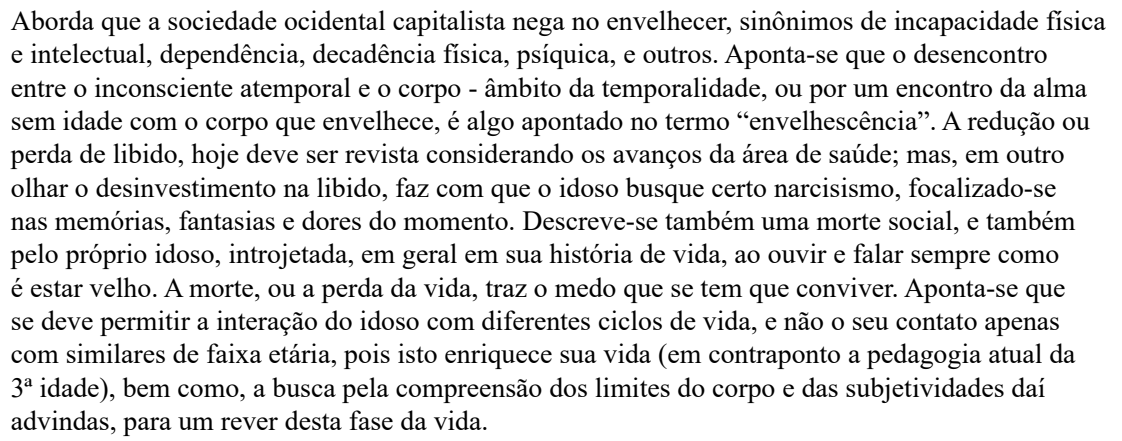 \\
\hline $\begin{array}{l}\text { Lima PMR, Viana } \\
\text { TC, Lazzarini ER. } \\
\text { "Velhice? Acho } \\
\text { ótima, considerando a } \\
\text { alternativa": reflexões } \\
\text { sobre velhice e } \\
\text { humor. Rev Mal-estar } \\
\text { e Subjetividade. } \\
\text { 2011; 11(4):1597-618 }\end{array}$ & $\begin{array}{l}\text { Esta é uma produção } \\
\text { do tipo reflexão que } \\
\text { busca articular a } \\
\text { noção de humor, a } \\
\text { partir da psicanálise, } \\
\text { e a velhice. }\end{array}$ & $\begin{array}{l}\text { O texto refere que a velhice é vista e vivida de forma negativa e que há uma busca incessante pela } \\
\text { felicidade e negação do sofrimento e da morte. Em Freud (Mal Estar da Civilização) os autores } \\
\text { apontam que o sofrimento se dá por } 3 \text { vias: pelo corpo, pelo mundo externo e pelas relações com } \\
\text { os outros; mas na atualidade isto é negado. Outrossim, relata-se a perda de posição do idosos, } \\
\text { na economia e na dimensão simbólica e existencial da sociedade, gerando por vezes isolamento } \\
\text { e alterações psíquicas. Citando Birman, se descreve a vinda de depressão, paranoias e manias. } \\
\text { Apresentam-se exemplos da vida de Freud com o uso de humor irônico para o alívio de sofrimentos } \\
\text { e uma tolerância saudável as ambiguidades e incoerências da vida. Cita ainda pesquisas realizadas } \\
\text { a partir de uma perspectiva psicanalítica que têm demonstrado auxílio ao velho a encarar a própria } \\
\text { vida e a morte com serenidade e integridade do ego. }\end{array}$ \\
\hline
\end{tabular}

Tabela 3

Categoria 3 - Representação do Envelhecimento para Profissionais de Saúde à Luz da Psicanálise. 2011 a 2015.

\begin{tabular}{|c|c|c|}
\hline Referência & Proposta do Estudo & Sinopse \\
\hline $\begin{array}{l}\text { Simões CHD, } \\
\text { Ferreira-Teixeira MC, } \\
\text { Aiello-Vaisberg TMJ. } \\
\text { Imaginário coletivo } \\
\text { de profissionais de } \\
\text { saúde mental sobre } \\
\text { envelhecimento. } \\
\text { Boletim de Psicologia. } \\
\text { 2014; 64(140): 65-77. }\end{array}$ & $\begin{array}{l}\text { Trata-se uma pesquisa qualitativa, com vistas } \\
\text { a investigar do ponto de vista psicanalítico o } \\
\text { imaginário coletivo de } 17 \text { trabalhadores de saúde } \\
\text { mental e de nível superior de um hospital dia, do } \\
\text { interior do estado de São Paulo/Brasil, sobre o } \\
\text { envelhecimento. } \\
\text { Utilizaram-se fotografias de pessoas idosas e } \\
\text { se solicitou associações imaginativas à luz do } \\
\text { método psicanalítico. O artigo não apresenta o } \\
\text { período de coleta de dados. }\end{array}$ & $\begin{array}{l}\text { O primeiro campo de sentido afetivo-emocional foi: "Sofrimento } \\
\text { e solidão", bastante expressivos, organizam-se ao redor da crença } \\
\text { de que essa fase caracteriza-se essencialmente pelo sofrimento } \\
\text { emocional, perdas e isolamento. O segundo campo, denominado "A } \\
\text { idade não importa", se expressa de modo mais tênue, veiculando } \\
\text { timidamente a crença de que é possível ser idoso e viver de modo } \\
\text { prazeroso. Esse quadro aponta, na visão de profissionais de saúde } \\
\text { mental, que por um lado, o ser idoso é aquele que vive triste e } \\
\text { solitário e, poucos profissionais ao mesmo tempo veem modos de } \\
\text { vida criativo e saudáveis. }\end{array}$ \\
\hline
\end{tabular}

Tabela 4

Categoria 4 - Geracionalidade e Psiquismo. 2011 a 2015

\begin{tabular}{|c|c|c|}
\hline Referência & Proposta do Estudo & Sinopse \\
\hline $\begin{array}{l}\text { Hartmann IB, } \\
\text { Schestatsky S. } \\
\text { Transmissão do } \\
\text { psiquismo entre } \\
\text { as gerações. } \\
\text { Rev Bras de } \\
\text { Pscicoterapia. } \\
2011 ; 13(2): 92- \\
114 .\end{array}$ & $\begin{array}{l}\text { Este é um artigo do } \\
\text { tipo reflexão, com } \\
\text { apresentação de um } \\
\text { estudo de caso com } \\
\text { a ideia de abordar } \\
\text { a transmissão do } \\
\text { psiquismo entre } \\
\text { as gerações, nas } \\
\text { modalidades } \\
\text { intergeracional e } \\
\text { transgeracional. }\end{array}$ & $\begin{array}{l}\text { Os autores apontam a transmissão do psiquismo entre gerações, presente desde o início na obra } \\
\text { de Freud, e que teve nos últimos anos um novo impulso na psicanálise, com vários trabalhos } \\
\text { dedicados à articulação da realidade psíquica do sujeito singular com a realidade psíquica do } \\
\text { grupo, podendo enriquecer a compreensão do sofrimento psíquico. Citando vários autores aborda- } \\
\text { se a importância do outro na construção do psiquismo, bem como, aspectos herdados dos pais e } \\
\text { da família ampliada. Tal transmissão envolve tanto aspectos positivos quanto negativos. Cita o } \\
\text { caso de uma idosa que teve uma história de repetições geracionais desde o seus pais biológicos, } \\
\text { passando pelos pais adotivos e vários eventos que incluíam incesto entre as diferentes gerações, } \\
\text { negação (inconsciente e por vezes consciente) e segredo de fatos. Aponta que traumas psíquicos } \\
\text { não elaborados podem passar de gerações a gerações e que tais elaborações servem como uma ação } \\
\text { preventiva para as futuras gerações. }\end{array}$ \\
\hline
\end{tabular}




\section{DISCUSSÃO}

De acordo com os resultados apresentados na categoria Clínica Psicanalítica com Idosos, verifica-se que a psicanálise pode ajudar na compreensão das vivências típicas da velhice, mas também pode evidenciar sintomas e sentimentos negativos dessa fase da vida. Contudo, mesmo os aspectos negativos, relacionados às perdas e limitações, são possíveis de serem utilizados para a aplicabilidade da análise com idosos. Conforme mencionado por Fontoni, Oliveira e Kaneta (2014), que realizaram trabalhos com idosos em estado confusional, a atuação terapêutica com idosos não apenas é possível, como é recomendada para auxiliar o paciente, dando-lhe suporte nos períodos difíceis que podem surgir nessa fase da vida, assim como, auxiliando na consciência de si mesmo, e do mundo, mesmo quando se caminha para o fim da vida.

Trata-se de uma tarefa difícil e delicada para o analista que deve fazer a ponte entre os sintomas e a realidade do paciente idoso, mas voltando seu olhar muito mais para a idade do sintoma do que a idade do paciente (Mucida \& Pinto, 2014). Os sintomas apresentados na velhice não apareceram necessariamente devido à fase da vida que $o$ sujeito se encontra, mas sim, se constituíram como marcas importantes na sua história de vida. Assim, cabe ao analista criar uma relação com seu paciente idoso, de modo que os sintomas que são apresentados consigam se conectar aos aspectos saudáveis e preciosos da história de vida do paciente (Brasil, Barcelos, Arrais, \& Cárdenas, 2013).

Os resultados encontrados nos permitem inferir que, apesar das controvérsias, é possível a aplicabilidade da análise com idosos. Contudo, essa prática tende a exigir do analista a disposição e preparo para confrontar diversas projeções relacionadas ao fim da vida. Essas projeções podem se tornar ainda mais difíceis de lidar no caso do analista idoso que, de acordo com Chessick (2013), vivencia uma situação que precisa ter consciência da sua existência e uma atenção constante nos processos de transferência e contratransferência. $\mathrm{O}$ analista idoso pode ter a seu favor sua bagagem de experiências ao longo da vida, tanto pessoal quanto na clínica. Contudo, essa se trata de uma categoria pouco abordada que carece de mais estudos na área para se compreender as complexidades do trabalho do analista na terceira idade e a forma como o mesmo lida com sua própria fantasia de finitude.

Verifica-se, ainda, que, apesar de pouco difundida, a psicanálise com idosos está presente em algumas ILPI, e Charazac (2014) faz um convite a se pensar sobre o fazer do psicanalista nestes lugares. Segundo Rozendo e Justo (2012), existem inúmeras consequências da institucionalização de idosos para os mesmos e, as implicações subjetivas que essa permanência pode ter. Contudo, de acordo com Altman (2011) onde há ansiedade, medos e frustrações, é possível se reconhecer também a presença de vida que pulsa. Desta forma, embora a prática da psicanálise em instituições de longa permanência pareça fugir da prática clássica, quando se trata de idosos, o analista necessita estar aberto para fugir dos preceitos clássicos e cogitar uma mudança no setting, como: trabalhos feito em conjunto com famílias e, com equipes de cuidadores (Fontoni et al., 2014).

Nas poucas produções científicas que emergiram neste levantamento, verificou-se os rumos clínicos que a psicanálise com idosos tem usado: a história oral, a história de vida, os trabalhos com memória, as atividades grupais, o uso de perfil diagnóstico de Ana Freud, a inscrição do sintoma e a necessidade de sua interpretação pelo analista. Verificou-se que as produções apontam para a necessidade de intervenções que recriem rumos mais saudáveis para a vida do idoso.

Lima, Viana e Lima (2015) também apontam o uso de alternativas na prática psicanalítica, como a escrita, que pode auxiliar a dar vazão às pulsões do idoso, além de fornecer a possibilidade de interpretação e reinterpretação dos fatos da vida. A criatividade é apontada como uma possibilidade de um reolhar da velhice, também conexa ao fazer psicanalítico.

A psicanálise com idosos tem tomado diferentes rumos clínicos pelo que mostra a produção cientifica. No entanto, a escassez de estudos relacionando a clínica psicanalítica e a terceira idade pode estar intimamente ligada à falta de interesse, de forma velada, dos analistas em tratar esta questão. De acordo com Brasil et al. (2013), a terapia com idosos é também uma forma de promover saúde no idoso, sendo capaz de favorecer processos criativos que auxiliem o processo do envelhecimento, constituindo-se como importantes razões para o fomento de estudos na área.

Parece que, dentre as principais lacunas, está a necessidade de uma maior quantidade de estudos clínicos da psicanálise com idosos, bem como, do mapeamento de experiências com esta faixa etária, além da descrição de estudos de caso, comuns na história da psicanálise.

A segunda categoria, Abordagens Psicanaliticas do Envelhecimento, traz uma visão negativa em relação ao envelhecimento. Percebe-se que as abordagens psicanalíticas do envelhecimento trazem a preocupação e o medo que a sociedade em geral tem do envelhecer, o que gera fantasias negativas. De acordo com Cherix (2015), ao ouvir idosos, em geral, o conteúdo da fala é sobre perdas, morte, queixas e preocupações com seus corpos, de modo que esses aspectos podem embasar grande parte da concepção negativa que integra a fantasia em torno da velhice.

Lima, Viana e Lazzarini (2011) questionam como se vive em uma época na qual, além de não haver preparo para a velhice, tende-se a fugir e se tornar obcecado pela juventude. Essa afirmação nos faz refletir acerca da falta de estudos voltados às abordagens psicanalíticas do envelhecimento frente a priorização de outros estágios do ciclo de vida, em especial a adultez, mas também a infância e a adolescência. 
Em relação às lacunas do conhecimento, observa-se a necessidade de conhecer o que pensam os psicanalistas acerca desta relação com os idosos e se há dimensões psicanalíticas diferenciadas na terceira idade que busquem uma melhor forma de trabalhar com os sintomas e possíveis dificuldades cognitivas.

Para Rozendo e Justo (2012), existem algumas razões enraizadas para que a velhice não atraia o olhar da psicanálise de uma forma especial. O próprio Freud era cético em relação ao uso da psicanálise com idosos. Diversas teorias do desenvolvimento psicológico e psicanalítico não ultrapassam o período da adolescência, e a própria psicanálise aborda o período senil como o estancamento do desenvolvimento psicossexual. Desta forma, pode-se pensar sobre a necessidade de um reposicionamento da psicanálise em relação ao envelhecimento e o desenvolvimento de novos estudos.

Na terceira categoria, Representação do Envelhecimento para Profissionais de Saúde à Luz da Psicanálise, verificamse duas nuances de representações dos profissionais, uma em que as perdas, limitações e aspectos negativos são amplamente destacados, e outra, citada com menor conviç̧ão e proporção, na qual se apresenta a ideia de que idade não importa, sendo possível ser feliz em qualquer fase da vida. Nota-se que os profissionais da saúde percebem a terceira idade com diferentes concepções, mas a concepção negativa se destaca, demonstrando, conforme citado por Simões, Teixeira e Vaisberg (2014), como estes profissionais podem estar desmotivados frente ao cuidado com o paciente idoso.

Segundo Silva, Ogata e Oliveira (2015), as discussões acerca da representação social do envelhecimento na perspectiva da saúde são novas e escassas e demonstram a fragilidade do sistema de saúde perante a uma faixa etária que não para de crescer. Assim, nota-se a importância de reconhecer as percepções destes profissionais, especialmente os da saúde mental, sobre o envelhecimento e a necessidade de que revejam seus conceitos sobre a velhice no intuito de despertar para novas práticas de cuidado com os pacientes, na tentativa de se descobrir possibilidades e potencialidades na velhice.

Defende-se aqui que a psicanálise pode contribuir não só com novos olhares de profissionais de saúde para suas práticas, mas também, em uma mudança de práxis na ILPI, ou outras instituições que atendam ao idoso. Existem diversas lacunas na produção científica no que diz respeito ao trabalho que a psicanálise pode estar desenvolvendo para além do consultório, fazendo algo diferente da prática tradicional, mas sem perder as bases epistemológicas que a caracterizam.

Na quarta categoria, Geracionalidade e Psiquismo, aponta-se a transmissão do psiquismo nas diferentes relações e a implicação que os aspectos herdados dos pais e da família ampliada tem sob a vida e o desenvolvimento dos indivíduos, mesmo na fase idosa. Silva, Rocha, Bobato, Beckeri e Lorenzetti (2015) pontuam que, dentre as funções do aparelho psíquico familiar, destaca-se a transmissão na sucessão de gerações, pela qual cada família transfere sua forma de entender, apreender e organizar o mundo externo. Assim, traumas psíquicos não elaborados podem passar de geração em geração e, de acordo com Lisboa e FéresCarneiro (2015), é comum que as pessoas associem doenças atuais com a história familiar, na convivência com outras pessoas doentes desse grupo.

Porém, nota-se a baixa inserção da psicanálise nesta área de estudo e a quase inexistência de outros estudos, mesmo que de outras áreas, sobre uma temática tão significativa. Lisboa e Féres-Carneiro (2015) pontuam que esta é uma área que, se apresentasse mais estudos, traria muitos benefícios, pois compreender o funcionamento familiar pode ser considerado um trabalho de prevenção de agravos e promoção da saúde, capaz de evitar somatizações e sofrimentos psíquicos diversos.

As diversas lacunas observadas na produção científica sobre a psicanálise e idosos, nas categorias que emergiram, assim como, as poucas pesquisas, comparando-se com populações de outras faixas etárias como crianças, adolescentes e adultos, reportam a necessidade de ampliação desta relação.

Algumas produções antigas da área, apesar de extremamente importantes, já se tornaram desatualizadas, o que pode nos tornar reféns de visões clássicas e nos impedir de enxergar as atuais nuances entre psicanálise e o processo do envelhecimento. Já sabemos que a prática psicanalítica pode contribuir, então, para o processo de envelhecimento e a vivência dos idosos. Assim, tendo em vista o aumento da expectativa de vida e, consequentemente, do número de pessoas idosas, torna-se de fundamental importância o desenvolvimento de mais pesquisas e estudos na área, a fim de compreender, adaptar e desenvolver o fazer psicanalítico com idosos, capaz de levar a descoberta de potencialidades e possibilidades nessa fase da vida.

\section{CONSIDERAÇÕES FINAIS}

É notável que existem poucos estudos que relacionem a psicanálise e o idoso. Além disso, das produções encontradas, poucas se constituem enquanto pesquisa, o que nos mostra o baixo interesse acerca da produção de conhecimento na área, mesmo a se considerar que o escopo epistemológico da área possa ser diferente.

A dimensão clínica foi o tema mais valorizado, mas, apesar de sua importância, talvez prescinda de outros 
elementos constitutivos, como a própria aceitação do psicanalista em atuar com idosos. Aspectos essenciais da psicanálise amplamente discutidos em outros ciclos de vida (como a sexualidade, a associação livre de ideias, o sintoma e sua relação cronológica temporal, dentre tantos outros) precisam ser adaptados ao processo de envelhecimento, tanto no que se refere à representação que estes tenham, como na adaptação contemporânea do idoso que temos, e do idoso que podemos ter no futuro.
A pessoa idosa é, sem dúvidas, uma importante demanda para a psicanálise na atualidade e, dessa forma, a área precisa repensar sua inserção neste campo de atuação. Por outro lado, a comunidade e os periódicos científicos precisam criar movimentos pendulares (de diálogo, de ir e vir, de crítica) que estimulem não só a produção e interesse da psicanálise no envelhecimento, como a formação de psicanalistas também interessados em atuar com este grupo, demanda que possivelmente será destaque das novas décadas.

\section{REFERÊNCIAS}

Alencar, D. L., Marques, A. P. O., Leal, M. C. C., \& Vieira, J. C. M. (2014). Fatores que interferem na sexualidade de idosos: uma revisão integrativa. Ciência e Saúde Coletiva, 19(8), 3533-3542.

Altman, M. (2011). O envelhecimento à luz da psicanálise. Jornal de Psicanálise, 44(80), 193-206.

Brasil, K. T. R., Barcelos, M. A. R., Arrais, A. R., \& Cárdenas, C. J. (2013). A clínica do envelhecimento: Desafios e reflexões para prática psicológica com idosos. Aletheia, 40, 120-133.

Brasil. (2010). Censo Demográfico 2010. Recuperado de http:// www.censo2010.ibge.gov.br

Charazac, P. M. (2014). L'apport de la psychanalyse aux soins en institution gériatrique. Gériatrie et Psychologie Neuropsychiatrie du Vieillissement, 12(2), 193-198.

Chase, C. (2011). The aging of Anna Freud's diagnostic profile: A re-examination and re-application of the psychoanalytic assessment for older adults. The Psychoanalytic Study of the Child, 65, 245-274.

Cherix, K. (2015). Corpo e envelhecimento: uma perspectiva psicanalítica. Revista da SBPH, 18(1), 39-51.

Chessick, R. D. (2013). Special problems for the elderly psychoanalyst in the psychoanalytic process. Journal of the American Psychoanalytic Association, 61(1), 67-93.

Fontoni, M. R., Oliveira, W. L., \& Kaneta, C. N. (2014). Winnicotti e o desafio do atendimento a pacientes idosos em estado confusional. Psicologia, Saúde \& Doenças, 15(3), 816-827.

Hartmann, I. B., \& Schestatsky, S. (2011). Transmissão do psiquismo entre as gerações. Revista Brasileira de Psicoterapia, 13(2), 92-1114.
Lima, P. M. R., Viana, T. C., \& Lazzarini, E. R. (2011). "Velhice? Acho ótima, considerando a alternativa": reflexões sobre velhice e humor. Mal-estar e Subjetividade, 11(4), 1597-1618.

Lima, P. M. R., Viana, T. C., \& Lima, S. C. (2015). Estética e poética da velhice em narrativas autobiográficas: um estudo a luz da psicanálise. Estudos e Pesquisas em Psicologia, 15(1), 58-78.

Lisboa, A. V., \& Féres-Carneiro. (2015). Acontecimentos significativos na história geracional e sua relação com somatizações na família. Psicologia: Teoria e Pesquisa, 31(1), $65-72$.

Mucida, A., \& Pinto, J. M. (2014). Sintomas de velhos?. Cadernos de Psicanálise, 36(30), 45-60.

Rozendo, A. S., \& Justo, J. S. (2012). Institucionalização da velhice e regressão: um olhar psicanalítico sobre os asilos de velhos. Revista Kairós Gerontologia, 15(8), 25-51.

Silva, B. R., \& Finocchio, A. L. (2011). A velhice como marca da atualidade: Uma visão psicanalítica. Vínculo, 8(2), 22-28.

Silva, E. C., Rocha, R., Bobato, S. T., Beckeri, A. P. S., \& Lorenzetti, N. (2015). Heranças psíquicas geracionais e a conjugalidade contemporânea: uma revisão sistemática. Pensando Famílias, 19(1), 19-31.

Silva, M. C., Ogata, M. N., \& Oliveira, D. C. (2015). O estado de arte das produções científicas nacionais das representações sociais do envelhecimento na perspectiva da saúde. Revista Kairós Gerontologia, 18, 49-63.

Simões, C. H. D., Ferreira-Teixeira, M. C., \& Aiello-Vaisberg, T. M. J. (2014). Imaginário coletivo de profissionais de saúde mental sobre envelhecimento. Boletim de Psicologia, 64(140), 65-77.

Vilhena, J., Novaes, J. V., \& Rosa, C, M. (2014). A sombra de um corpo, imagem e envelhecimento. Revista Latinoamericana de Psicopatologia Fundamental, 17(2), 251-264. 